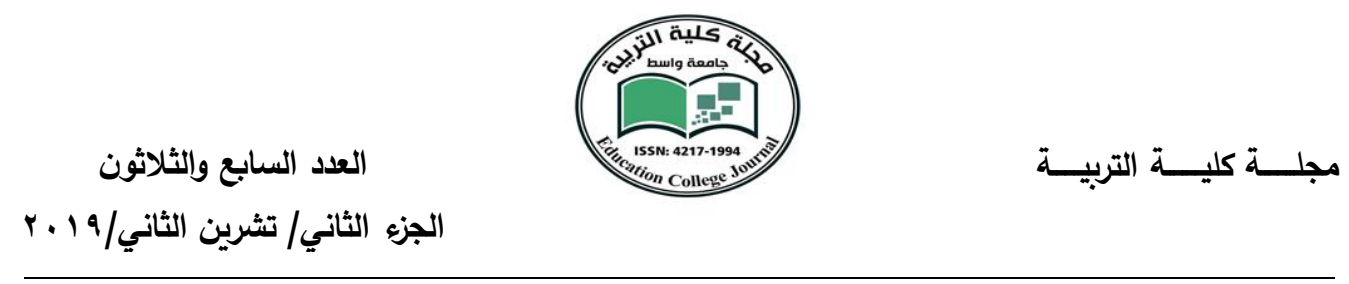

\title{
The Significance of Political Neologisms
}

Saja Abdul Ameer Hadi

MA Student of Language and Linguistics, Wasit University

Ali Muhsin Gharab AL-Majdawi (Ph. D.)

Assistant Professor, Department of English, Wasit University

\begin{abstract}
Almost all political vocabularies were neologisms. The present study aimed to show the importance of neologisms in political language. Neologisms are considered as the essential part of everyday speech. So, the main goal is to show the reasons behind the creation of neologisms that have gained new senses through political, social, economic and cultural changes in society. It points out the influence of political life upon culture and how culture helps politicians in producing political neologisms. The study analyses these neologisms in order to give more understanding information about them. The study concludes that people who work in the political field use neologisms to give a hidden message or to refer to the opposite of what they mean.
\end{abstract}

\section{الخُلاصة}

على الأغلب فأن جميع المفردات السياسية مُستحدثة. لذا فالدراسة الحالية تَهدف لِبيان أهمية تلك

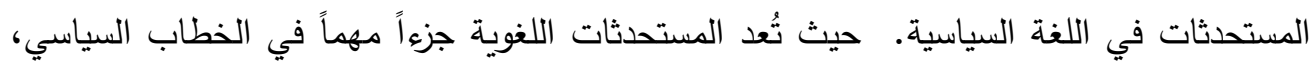

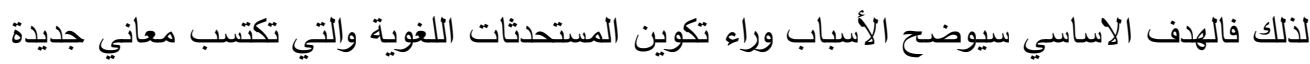

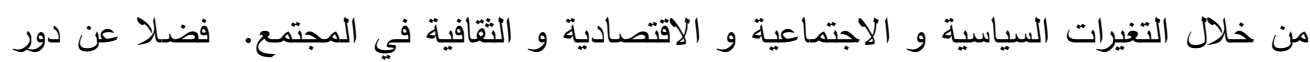

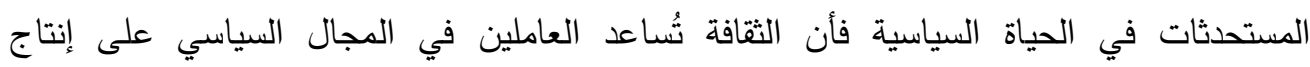

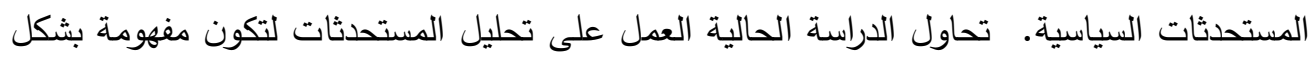

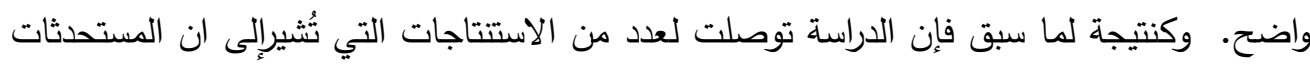

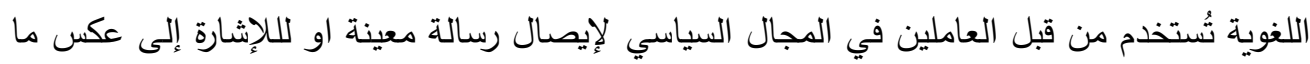

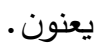



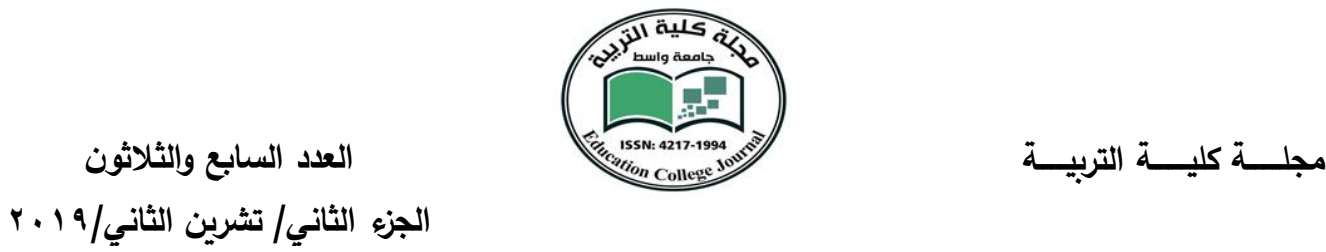

\section{Introduction}

People identify themselves through their use of language. They refer to language as a social identity. Thus, people communicate with each other by using language and they use it to describe their experience and culture. Political neologisms face a lack of the equivalents in the target language and these neologisms are not found in dictionaries. The people who work in the political field use neologisms in order to give hidden message.

\section{Neologism}

Choi (2006) states that neologism is defined as " words that have been newly created" and " new words and phrases that are used commonly in speech, but not included in dictionaries are also regarded as neologisms" ( p. 189). Rey (1995) states that neologism is:

A unit of the lexicon, a word element or phrase whose meaning, or whose signifier-signified relationship, presupposing an effective function in a specific model of communication, was not previously materialized as a linguistic form in the immediately preceding stage of the language. (p. 77)

According to the view of Stekauer (2002), a neologism is "a naming unit which was coined to satisfy a linguistic demand, be it the demand of a single member of speech community, or a single unrepeated demand" (p. 101). So, the idea of creating neologisms is a result of the needs of a speech community. Neologisms have been used for purposes related to political, social and economic ends. The idea of Stekauer is supported by Cabre (1999) who mentions that the aim of terminographers is to assign names to concepts which move from the concept to the term, by contrast, lexicographers start with the word and characterize it functionally and semantically, which refers to move from word to the concept. Thus, creating new words is a basic need in changing world.

Cabre (1999) gives four criteria for defining neologism. These criteria are: a psychological criterion, a lexicographic criterion, a diachronic criterion, and a criterion which depends on a word that showing a systematic signs of semantic instability. She declares that these criteria cannot work alone to 

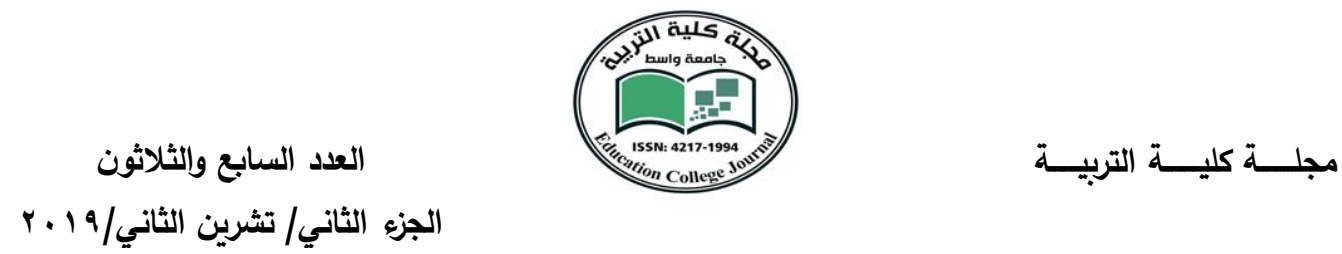

give a perfect identity to the phenomenon. But these criteria combine together to give the definition of neologisms.

Psychological Definition: neologism is a new word. It is found in dictionaries. It is intended to make new words in language as it is defined by Plag (2005) as a newly created linguistic expression that is known by part of the linguistic community. Cabre (1999) defines psychological criteria depending on Rey's point of view. To Cabre, neologism is a word that can be understood by the language community.

The word in the new lexicon compares with a word in the old one. Some words are older than others, but there is no exact date for being new. There is no stable lexicon as opposite to those that are new (Rey, 1995).

Lexicographic Definition: the clearest source of list of words in language is lexicographic vocabularies and dictionaries. Neologisms can be defined here as any word that does not appear in the dictionary should be considered as neologism (Cabre, 1999).

Diachronic Definition: the direct relation between the notion of the newness and the definition of a neologism is the lack in the lexicographic definition. The diachronic criterion is the main factor in the definition of a neologism. As Cabre (1999) states that a neologism refers to any word-form that occurs in language recently and was not part of language. The difficulty in the diachronic definition, that it does not give which words are new on one hand, and which words are parts of language on the other hand. Dictionaries are not appropriate devices to define the term of neologism. The diachronic criterion is considered as the backbone to the lexicographic definition. Thus, the words that do not emerge in the dictionary due to the fact that these words are recent, these words can be considered as neologisms. Cabre (1999) states that the best way to define neologism is a "hybrid" approach which refers to all the criteria together With all definitions of neologism, creation is agreed particularly in the form and meaning of neologism. This creation begins with three types of neologisms. Both Rey and Cabre agree on the classification of neologisms into three categories. These are: Proper neologisms, Pseudo neologisms, and Semantic neologisms. 

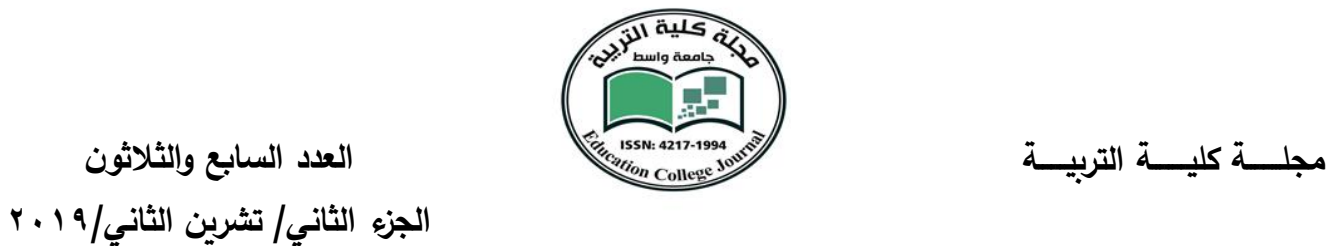

Proper neologisms refer to the completely new term with a new sense such as: 'Bushilla', 'Mother of All Battles', '9/11'.

Pseudo neologisms refer to a new sense that can be used with the old sense, both of a new sense and the old one include the same.

Semantic neologisms refer to the change of meaning due to the old sense which is wholly substituted with a new one. It considers neologisms when a large group of users aware of it (Rey, 1995). Newmark (1988) states that neologisms can be defined as "newly coined lexical units or existing lexical units that acquire a new sense" (p. 140). He refers to the types of neologisms: old words with new sense, derived words, new coinage, collocation, eponyms, abbreviations, phrasal words, transferred words, acronyms and pseudo neologisms. These types form difficulties to the translator and these types cannot be found in dictionaries. Thus, the translator himself creates new words and expressions during the process of translation.

Newmark (1988) mentions that "any kind of neologism should be recreated; if it is a derived word it should be replaced by the same or equivalent morphemes, if it is also phonaesthetic, it should be given phonemes producing analogous sound effects" (p. 143).

\section{Political Language}

Political language is considered as an effective device that not only gives the expansion of political information, but also regards the essential expression of political notion. Neologism is a feature of language and refers to the source of knowledge of political world. Neologisms provide the name of the new idea that occurs in the political life of the society. They appear during the actualization of some events and connect with change in economic, political and other areas. Both Jeffries (2006) and Westbrook (2012) point out that change in politics, demography, society and economy conditions the society and the language it uses.

In general, the forces of politics and economics are viewed as "the chief determiners for providing the framework for terminological activities as well as the means for their realisation" (Rey, 1995, p.50). There are many neologisms in political language that refer to the new political structures and 

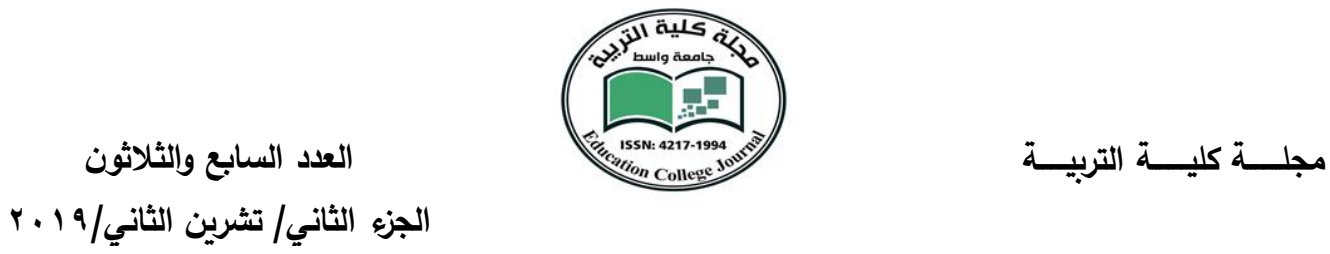

the international global politics. The suitable use of the language is a source of power to understand messages that are unspoken which lie behind the spoken threats. Political language can be found in newspapers, media and dictionaries. During the development of language, many neologisms appear in the language, but some of them are fixed in language. The formation of new words which are known neologisms in political dictionary is due to the fact of conversation between government and society. In language, $\mathrm{x}$ phemisims contain orthophemism, dysphemism and euphemism. Orthophemism refers to straight talking; dysphemism refers to offensive talking, while euphemism refers to sweet talking. Language users flattered and commanded by politics to adopt replacements for words. Neologisms can be produced by politicians by renaming war tricks. Renewal or reinvention is one of the central functions of modern politics (Richardson, 2007). Thus, the term of war uses euphemistic words to mask the violence for instance, (Desert Storm) is a euphemistic word for war. It is a compound word of two nouns which is regarded as the code name of (Gulf War). Gulf War is a war name which is a compound of two nouns. McMahon (1995) points out that Hughes who refers to the development of English political vocabulary due to the change in its principles from "the commands of kings... to the discussion and persuasion of elected governments" such as (Eurozone). Eurozone is a clipping noun from two nouns which are (Europe) and (Zone), Eurozone refers to the countries that are using euro (Oxford English Dictionary, 2018).

\section{Language Change}

Both Algeo (1993) and Jeffries (2006) assert that English language is used to reflect social, political, and cultural history of people and moves. Users of language adopt and try to generalize innovations during the speech community in order to change the meaning of words to make them suitable with new conditions to be spread in the system (Booij, 2005; Saeed, 2009).Aitchison (2013) explains that the change of language happens in two ways: conscious and unconscious. Language changes in conscious way refer to the pressures from above; this means that language users are aware about the change due to the ideas come to conscious awareness. Thus, the ideas are received by mind from the surroundings and then new words are neolouged. 


\section{العداد السابع والثلاثون

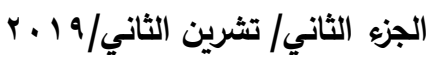
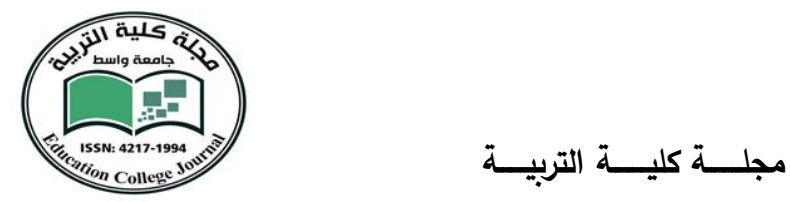

While unconscious changes spread without awareness that is known as pressures from below. This change is never noticed by people. Language change is ensured in which language is passed on from one generation to another If language feels the need, it makes the new word. Rey (1995) is aware of this need supposing that "every model needs a terminology adapted to its purpose .... Every change in the system of knowledge requires parallel changes in the system of designation" (p. 56). Linguists are weak to elaborate language. They think that when a word is created, it makes economy of discourse. So, the word is repeated in the society, and then it is accepted. Bauer (2002) states that both productivity and creativity create a large number of neologisms. Politicians are considered the master of producing words that are used through their campaign to skillfully effect the minds of voters. Neologisms may refer to the character of the speaker. For instance, the term Bushism refers to the weak character for George Bush and this weak character can be found during words, phrases, pronunciations and linguistic errors in public speaking. The term Bushism becomes the basis of published books and is used to refer to caricature Bush. The noun Bushism is a neologism which consists of the proper noun (Bush) and the suffix -ism (Amitima, 2006).

\section{Methodology}

Many theorists have focused on the problem of neology. While others such as Cabre, Newmark and Rey have concentrated on the division of neologisms depending on function or type. Cabre (1999) makes a step identical to the procedure of Rey. This step includes the following:

1. Functional neologisms.

2. Semantic neologisms which contain extension, restriction and others.

3. Neologisms that are borrowed.

4. Neologisms in form including derivations, compound and shortening.

The selection of data is based on an essential criterion which is the content because the analysis is especially thematic. The content is a number of items of political neologisms. Cabre (1999) mentions four criteria to clarify neologisms 


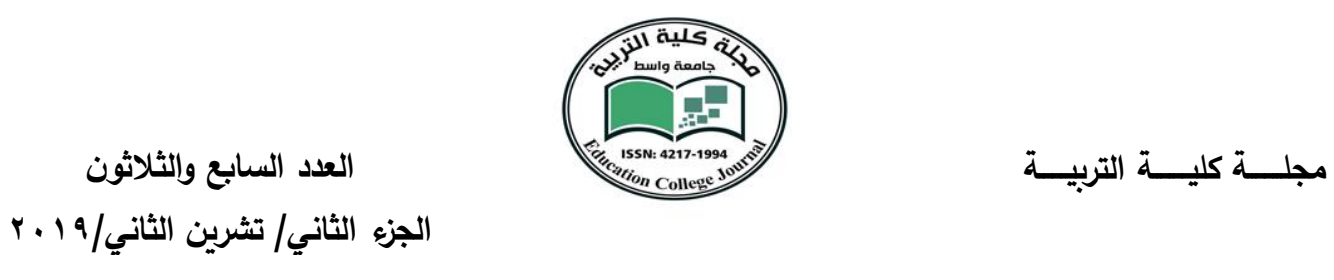

\section{Theoretical Framework}

This study depends on Cabre (1999) in analysing political neologisms. The study is based on four stages in analysing political neologisms. The first one represents the creation stage. The second one illustrates the trail stage. The third one focuses on the establishment stage. The fourth one deals with the documented stage. Neologisms are either referential neologisms or expressive neologisms. Referential neologisms develop in order to fill the gap in a special field. While expressive neologisms develop to give new form.

a. The Creation Stage, in this stage, the word is kept in the short memory of a group of the users of language. It refers to the two types of neologisms which are hapaxes and nonces. Thus, the creation phase is said once for a purpose as hapaxes and nonces. In other words, it is quite new and used by very few subcultures. For example,

"Outpost of Tyranny" this phrase is a coinage and it is an expressive term used to refer to special purpose. It is coined and used in 2005 by the United States Secretary of state Condoleezza Rice to describe six outpost of tyranny around the world such as: North Korea, Iran, Cuba, Burma, Belarus, and Zimbabwe (Pal, 2005).

b. The Trail Stage, in this stage is spread, but it is not yet accepted yet. It refers to the spread of lexical words in short time. Such a word is used in specific situation by the users of language, for example:

"Youthquacke" which is a compounding of two nouns 'youth' and 'quake'. It is a referential term as a retronym to denote the change by young people. It is the word of 2017, and it refers to the political, social, and cultural change as the result of the actions of the young people. This term is used firstly in June during the general election of UK, where the general election of UK refers to the supporting of opposition Parties by young voters (Cain, 2017).

c. The Establishment Stage, this stage refers to a word that acquires agreement because it is stable, and it is not recorded in the dictionaries. The 


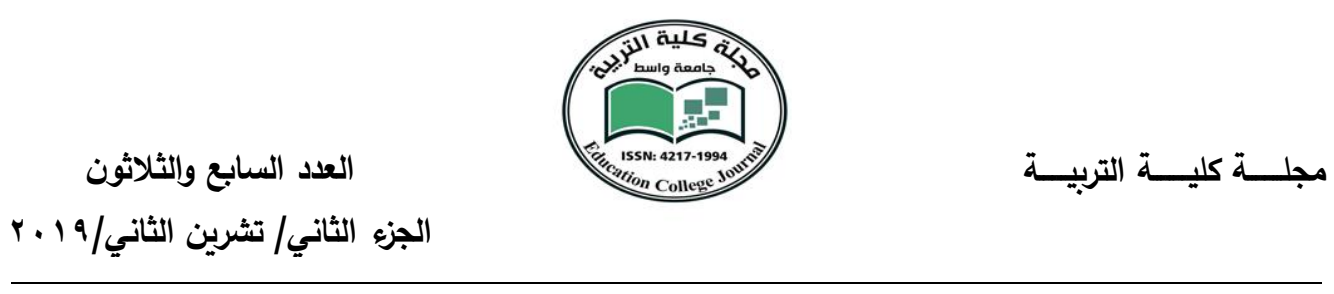

words in this stage appear on large scale in discourses and texts. For example,

"Antifa" it is a blending of 'anti' and 'fascist' or 'fascism'. It is a referential term as Retronym used to denote the opposition for the ideologies and individuals are belonging to fascist. This term is appeared at the end of World War I, and even the present day. This term is founded and supported by Benito Mussolini on March 23, 1919 to April 28, 1945 in Italy in order to oppose the system of governance at that time. There are other systems that have the same approach of fascism which opposed the thoughts of Hitler which represent the ideologies of Nazi Party as well as extreme right-wing ideology (Jaffe, 2017).

The Documented Stage, this stage refers to new words which are widespread, and they are recorded in the official dictionaries. The example about such a stage is:

"Obamacare". It is a compounding of two nouns, 'Obama' and 'care'. It is a referential term used to refer to repair health care system in America. This term is suggested by the president Barack Obama in 2010, to reform the health care system in the United States. This law is considered as the first law to Obama after his inauguration as president of the United States. The aim of this law is to provide health insurance with law costs (Seth, n.d.).

\section{Conclusion}

As time passes, language changes due to the changes in cultural, social, political and economic factors. English language is full of new words and concepts. It is regarded as the exporting language for new terms, while many other languages are considered as importers of these new terms and concepts. As a result, the study exposes some conclusions that prove the importance of neologisms and its role in promoting language which is inspired via sociocultural realities. In addition, people who work in the political field use neologisms to give a hidden message or to refer to the opposite of what they mean. Political neologisms that are commonly used in one culture are not 

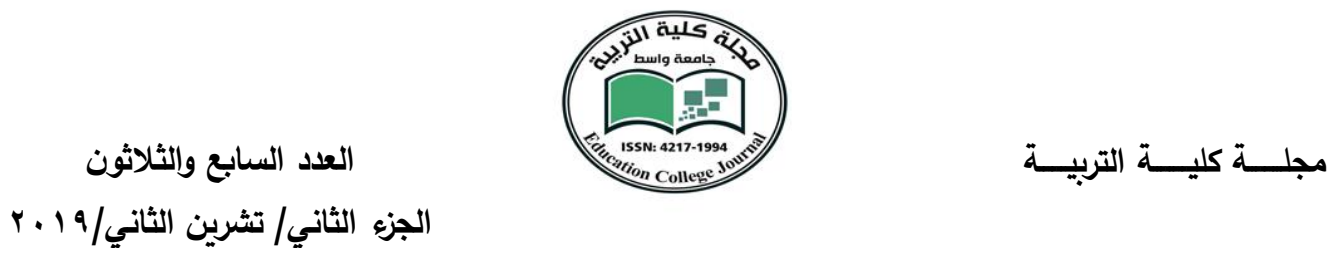

found in another culture. As well as these neologisms that are transmitted to English and used after have been described, such neologisms become part of English, for example: 'Fatwa' and 'Intifada' are found in the sources of English without more information about these neologisms.

\section{References}

Aitchison, J. (2013). Language change: Progress or decay? $\left(4^{\text {th }}\right.$ ed.). UK: Cambridge University Press.

Algeo, J. Ed. (1993). Fifty years among the new words: A dictionary of neologisms 19411991. USA: Cambridge UP

Amitima. (2006). Acquiescence. In Urban dictionary: Bushism. Retrieved from https://www.urbandictionary.com/define.

Bauer, L. (2002). English word-formation. Cambridge: Cambridge University Press.

Booij, G. (2005). The grammar of words: An introduction to linguistic morphology. Great Britain: Oxford UP.

Cabre, T. (1999). Terminology: Theory, methods and applications. Amsterdam: John Benjamin publishing Company.

Cain, S. (2017, December 14). 'Youthquacke' named 2017 word of the year by Oxford dictionaries. The Guardian. Retrieved from https://www.theguardian.com.

Choi, J. (2006). Interpreting neologisms used in Kores's rapidly changing society. Meta, 51.

Jaffe, S. (2017, September 13). The long history of Antifa. Retrieved from https://www.progressive.org/dispatches/thelonghistoryofantifa.

Jeffries, L. (2006). Discovering language: The structure of modern English. New York: Palgrave McMillan.

McMahon, A. (1995). Understanding language change. Cambridge: Cambridge University Press.

Newmark, P. (1988). A textbook of translation. London: Prentice Hall International (UK) Ltd.

Oxford English dictionary. (2018). Retrieved from https://www. oxforddictionaries.com.

Pal, A. (2005). 'Outposts of tyranny' list is selective. Retrieved from https://journal.probe International.org.

Rey, A. (1995). Essay on terminology. Trans. and Ed. Juan C. Sager. Amsterdam: John Benjamin Publishing.

Plag, I. (2005). Word-formation in English. Cambridge: Cambridge University Press.

Richardson, J. (2007). Analysing newspapers: An approach from critical discourse analysis.

New York: Palgrave Macmillan. 


\section{العدد السابع والثلاثون}
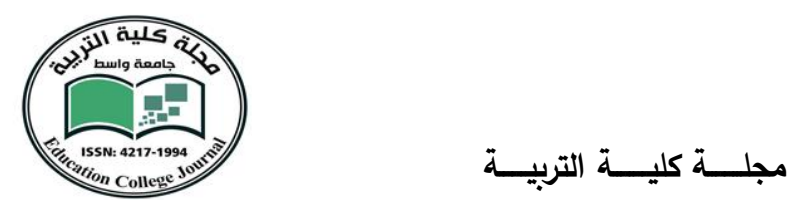

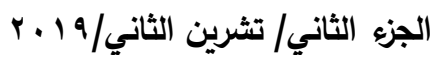

Saeed, J. (2009). Semantics ( $3^{\text {rd }}$ ed.). UK: Wiley-Blackwell.

Seth, S. (n.d.). 7 Industries benefiting from Obamacare. Retrieved from https://www.investopedia.com/articles.

Stekaner, P. (2002). On the theory of neologisms and nonce-formations. Australian Journal of Linguistics, 22, 1.

Westbrook, H. (2012). Eastwooding with the mother flame: The words of 2012. USA: Hugh Westbrook. 